Acta vet. scand. $1974,15,144-146$.

Brief Communication

\title{
STUDIES ON FASCIOLA HEPATICA MIRACIDIA LABELLED WITH RADIOSEIENIUM
}

Most previous information on host location by miracidia has been based on stereomicroscopical observations on the swimming behaviour of the larvae in the presence of snails and on the ability to attach, penetrate and develop in the host. Such studies are often tedious and time-consuming involving prolonged microscopy and serial sections of snails. Although the data obtained may describe the nature of the miracidium-snail contact, they usually provide only scanty quantitative information. The present paper describes a procedure for in vivo labelling of miracidia with radioselenium. A small-scale experimental set up exemplifies the application of labelled miracidia in studies on their hostfinding.

Conventional albino mice were experimentally infected with oral doses of 20 Fasciola hepatica metacercariae. Two to 3 months after inoculation some mice had died from the acute infection, but the majority survived despite surprisingly high fluke burdens ( $3-7$ adult parasites). In order to incorporate radioactivity in the parasite eggs, such heavily infected mice were given ${ }^{75} \mathrm{Se}-\mathrm{methionine}$ per os. Each mouse received 2 doses of

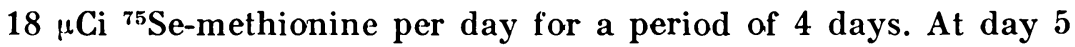
the mice were sacrificed, and eggs were harvested from the flukes by dissection under the stereomicroscope. Subsequently, the parasite eggs were incubated at $26^{\circ} \mathrm{C}$ for 16 days and then stimulated to hatch. The average amount of radioactivity confined to each miracidium corresponded to approx. 2 counts per minute (c.p.m.). Apparently, the motility of the labelled miracidia was unaltered and experimental infection of Lymnaea truncatula ( 5 miracidia per snail) showed that the larvae developed normally up to the metacercarial stage.

The labelled miracidia were used in experiments designed to study the attraction towards various snail species. Specimens of Lymnaea truncatula, Lymnaea pereger, Lymnaea palustris, 
Aplexa hypnorum and Physa acuta were employed. The experiment comprised 2 different systems. In the first system all 5 species were placed in the same plastic beaker, containing approx. 600 miracidia in $100 \mathrm{ml}$ of water. In the other system the snails were placed in separate beakers containing 600 miracidia in 100 $\mathrm{ml}$ of water. All snails were of comparable size, i.e. approx. 4-5 $\mathrm{mm}$ in length. They were kept in a vertical position in the center of the beakers by means of a thin wooden stick fixed to the top of the shell by nail-laquer. At intervals after the exposure to the miracidia the snails were removed from the beakers and transferred to a scintillation well counter. Subsequently they were returned to the respective miracidia suspensions. Results from 1 experiment are listed in Table 1.

T a b l e 1. Radioactivity (c.p.m.) in individual snails exposed to labelled Fasciola hepatica miracidia.

\begin{tabular}{|c|c|c|c|c|c|c|}
\hline & \multicolumn{3}{|c|}{ Snails in same beaker } & \multicolumn{3}{|c|}{ Snails in separate beakers } \\
\hline & $1 / 2 \mathrm{hr}$. & $3 \mathrm{hrs}$. & $20 \mathrm{hrs}$. & $1 / 2 \mathrm{hr}$. & $3 \mathrm{hrs}$. & $20 \mathrm{hrs}$. \\
\hline L. truncatula & 49 & 114 & 126 & 35 & 99 & 260 \\
\hline L. pereger & 8 & 17 & 18 & 27 & 7.0 & 214 \\
\hline L. palustris & 15 & 33 & 51 & 22 & 57 & 102 \\
\hline A. hypnorum & 0 & 0 & 0 & 0 & 0 & 0 \\
\hline P. acuta & 0 & 0 & 0 & 0 & 0 & 0 \\
\hline
\end{tabular}

The radioactivity determinations from this and repeated experiments clearly show that $F$. hepatica miracidia do not attach A. hypnorum or P. acuta. All 3 lymnaeid species attract miracidia although there seems to be a predilection for $L$. truncatula (the normal host). This latter finding is consonant with studies by Neuhaus (1953). Measurable radioactivity is found in the snails already after $1 / 2 \mathrm{hr}$. and is increasing to a maximum at approx. $20 \mathrm{hrs}$. At this time, where motile miracidia are very few, no further radioactivity is incorparated in the snails. The infected snails survived for approx. 1 week or more. The data listed allow no conclusive interpretation of the observed difference between the relative uptake of miracidia by the 3 lymnaeid species in mixture as compared with separate exposure.

The procedures described here provide a useful and sensitive experimental model in studies on various aspects of host-location by trematode miracidia. 
Peter Nansen

The Danish Agricultural and Veterinary Research Council, Parasitological Research Group,

Institute of Internal Medicine,

Royal Veterinary and Agricultural University,

Copenhagen, and

Flemming Frandsen

The Danish Bilharziasis Laboratory, Charlottenlund, Copenhagen, Denmark.

\section{REFERENCES}

Neuhaus, W.: Uber den chemischen Sinn der Miracidien von Fasciola hepatica. (Studies on the chemical sensitivity of Fasciola hepatica miracidia). Z. Parasitenk. 1953, 15, 476-490.

(Received February 25, 197/).

Reprints may be requested from: Peter Nansen, The Institute of Internal Medicine, Royal Veterinary and Agricultural University, DK-1870 Copenhagen V, Denmark. 